\title{
Gerenciamento Participativo em Saúde do Trabalhador: uma experiência na atividade de controle de vetores'
}

\section{Participative Management in Workers' Health: an experience in the vector control activity}

\author{
Rodolfo Andrade de Gouveia Vilela \\ Engenheiro. Doutor em Saúde Coletiva. Professor da Faculdade de \\ Saúde Pública da Universidade de São Paulo. \\ Endereço: Av. Dr. Arnaldo, 715, Cerqueira Cesar, CEP 01246-904, \\ São Paulo, SP, Brasil. \\ E-mail: ravilelaœusp.br

\section{Maria Elizabeth Malagoli} \\ Médica do Trabalho da Dacarto Benvic e Gerente de Saúde Ocu- \\ pacional da COMGÁs de São Paulo. \\ Endereço: Rua Olimpíadas, 205, 10 andar, Vila Olímpia, CEP 04551- \\ ০oo, São Paulo, SP, Brasil. \\ E-mail: emalagoliðgmail.com \\ Luiz Carlos Morrone \\ Professor Doutor da Faculdade de Medicina da Santa Casa de Mi- \\ sericórdia. Departamento de Medicina Social e Centro de Estudos \\ Augusto Leopoldo Ayrosa Galvão (CEALAG-SP). \\ Endereço: Rua Dr. Cesário Mota Jr., 61, Vila Buarque, CEP 01221-020 \\ São Paulo, SP, Brasil. \\ E-mail: morronelcœuol.com.br \\ I Resumo desta experiência foi apresentado no 27 Congresso \\ Internacional de Saúde Ocupacional - ICOH 2003, realizado no \\ período de 23 a 28 de fevereiro de 2003.
}

\section{Resumo}

Este artigo apresenta a experiência de implantação de um sistema de gestão em Saúde do Trabalhador implantado na Superintendencia de Controle de Endemias (SUCEN), no período de 1998 a 2002, que operava na atividade de controle químico de vetores no Estado de São Paulo. Objetivo: Descrever o sistema de gestão participativa, as ações desenvolvidas e os principais resultados alcançados. Método: Relato da experiência vivenciada pela equipe usando abordagem qualitativa, análise de documentos e apresentação de dados quantitativos. Resultados: Foram eleitas 11 Comissões de Saúde e Trabalho (COMSAT's) que em conjunto com a equipe técnica iniciaram a identificação dos riscos e de propostas para prevenção e controle dos riscos no trabalho. 0 mapeamento de riscos resultou em 650 recomendações, $45,7 \%$ das quais foram executadas. Foram identificadas como doenças relacionadas ao trabalho: reações alérgicas aos pesticidas, lesões por esforços repetitivos, distúrbios auditivos e patologias de coluna vertebral. Participaram dos cursos básicos de saúde do trabalhador 1.003 servidores $(76,3 \%$ do total de servidores), sendo que 90,8\% dos participantes os consideraram ótimos ou bons. Conclusões: O sistema de gerenciamento participativo coloca em prática os princípios de gestão democrática do Sistema Único de Saúde (SUS); incorpora, por meio do mapeamento de riscos, o saber do trabalhador; inclui os trabalhadores como sujeitos do processo de negociação e mudanças; pratica o direito à informação. As COMSAT's revelaram-se espaços adequados para a negociação das melhorias nas condições de trabalho. A aprovação do sistema de gestão culminou na validação legal por meio de um acordo tripartite assinado em março de 2002. 


\section{Palavras-chave: Saúde do Trabalhador; Gerencia- mento de riscos; Ambiente de trabalho; Exposição a praguicidas; Participação nas decisões.}

\section{Abstract}

Introduction: The paper shows the implementation experience of a management system in occupational health that took place at SUCEN (Superintendence for Endemic Control), from 1998 to 2002, which worked on the activity of chemical control of vectors in the State of São Paulo. Objective: To describe the participative management system, the actions that were taken and the main accomplished results. Methods: Report on what was experienced by the team using qualitative approach, document analysis and report on quantitative data. Results: Eleven COMSAT's (Workers Health Committees) were elected, which, together with the technical team, started to identify the occupational risks and proposals to prevent and control them. The investigation resulted in 65 o suggestions, $45.7 \%$ of which were carried out. Work-related diseases were identified as allergic reactions to pesticides, muscular pain linked to repetitive movements, hearing disorders and back pain caused by excessive weight carrying. A total of 1003 workers participated in the basic courses on workers health, $90.8 \%$ of whom classified them as good or excellent. Conclusions: The participative management system puts into practice the democratic management principles of SUS (Brazil's National Health System); by means of risk mapping, it incorporates workers' experiences; it regards workers as agents in the change and negotiation process; it puts into practice the right to information. The COMSAT's proved to be adequate places for negotiating improvements in working conditions. The approval of the Management System ended up in legal validation through a three-party agreement signed in March 2002.

Keywords: Occupational Health; Risk Manegement; Working Environment; Pesticide Exposure; Participation in Decisions. 


\section{Introdução}

Por gerenciamento participativo ou gerenciamento democrático em Saúde do Trabalhador entende-se o sistema gerencial baseado na participação ativa do trabalhador como sujeito do processo de controle dos agravos à saúde relacionados ao trabalho. Esta abordagem tem como uma das origens a Reforma Sanitária Italiana, ocorrida na década de 1970 naquele país, e teve os trabalhadores e seus representantes como protagonistas de lutas por melhorias das condições de trabalho. Um dos frutos dessa experiência é o método participativo aplicado no mapeamento dos riscos e nas negociações coletivas para a melhoria dos ambientes de trabalho. Entre os princípios desse modelo pode-se destacar o da não delegação ou da autotutela pelos trabalhadores do cuidado da sua saúde, ou seja, no controle e prevenção da nocividade oriunda dos ambientes e processos de trabalho (Oddone e col., 1986). Outras diretrizes e objetivos têm sido demandados principalmente pela experiência de parte do movimento sindical brasileiro como atributos básicos de um sistema democrático de gestão em saúde do trabalhador e meio ambiente, como o direito à informação - direito de saber; o direito à livre organização e de negociação das melhorias nos ambientes de trabalho; direito à recusa ao trabalho perigoso à saúde e ao meio ambiente; prioridade à prevenção e à eliminação dos riscos em sua origem; recusa aos processos de transferência e terceirização dos riscos para segmentos mais precarizados e de difícil controle; recusa aos adicionais que representam a venda e a compra da saúde (Vilela e Martins, 1996).

A saúde do trabalhador (ST) surge no Brasil na década de 80 no contexto da redemocratização do país. Ela se constitui enquanto um campo de conhecimento e de práticas inovadoras gestadas na aliança do movimento sanitário, sindical e de centros de pesquisa. A ST é influenciada pela Medicina Social Latino Americana, sofre influência da experiência Italiana e se contrapõe às práticas dominantes da Medicina do Trabalho e da Saúde Ocupacional, que até hoje são hegemônicas nas práticas dos serviços especializados de segurança e medicina do trabalho - SESMT de empresas (Minayo - Gomez e Thedin Costa, 1997).
Uma das principais críticas ao modelo de gestão convencional dos SESMTs é a manutenção do trabalhador na condição de objeto - corpo produtivo que deve ter comportamento normatizado e vigiado; uma condição de "paciente" e não de sujeito- agente do processo de mudança.

A Constituição Federal de 1988 definiu o sistema de gestão democrática, do controle social e da participação da comunidade como uma das bases fundamentais de organização do aparelho de Estado no que se refere ao funcionamento do Sistema Único de Saúde (SUS), conforme define o artigo 198 parágrafo. III, do Capítulo da Saúde. A Lei Federal no 8.142/9o cria em âmbito nacional o sistema democrático de gestão do SUS alicerçado nas Conferências e Conselhos como instâncias deliberativas sobre as políticas em cada âmbito de governo.

As diretrizes das ações de Vigilância em Saúde do Trabalhador no SUS foram consolidadas na Portaria Ministerial $n^{0}$ 3.120, de julho de 1998, que institui a Instrução Normativa sobre as Ações de Vigilância em Saúde do Trabalhador (Brasil, 1998), que prevê: a universalidade das ações, independentemente da existência de vínculos empregatícios formais no mercado de trabalho; a integralidade das ações compreendendo a assistência e a recuperação dos agravos, a prevenção por meio de intervenções nos processos de trabalho; a pluri-institucionalidade envolvendo as instâncias de vigilância em saúde do trabalhador, centros de atendimento e assistência, instituições, universidades e centros de pesquisa sobre saúde e ambiente; o controle social com a incorporação dos trabalhadores e seus representantes, em todas as etapas da vigilância em saúde do trabalhador; a hierarquização e descentralização consolidando o papel do município e dos distritos sanitários como instância de desenvolvimento de ações; a interdisciplinaridade incorporando as diversas áreas de conhecimento técnico com o saber operário; a pesquisa - intervenção como processo em que a pesquisa é parte integrante e indissolúvel, que subsidia e aprimora a própria intervenção; o caráter transformador - de intervenção sobre os fatores determinantes e condicionantes dos problemas de saúde relacionados aos processos e ambientes de trabalho.

Além dessas diretrizes, a experiência recente das negociações coletivas e de acordos tripartites 
nos temas de segurança e saúde do trabalhador tem mostrado a importância dessa estratégia para a melhoria nas condições de trabalho e para a democratização e modernização das relações de trabalho. As negociações coletivas na área de saúde e segurança do trabalho têm sido estimuladas pelo Ministério do Trabalho e Emprego e Ministério da Saúde, principalmente as negociações tripartites, com a presença de órgãos públicos, órgãos de representação dos trabalhadores, dos empregadores, resultando em normas ou acordos nacionais, regionais, municipais ou convenções coletivas (Bonciani, 1996; Vilela, 1998; Magrini, 1999). Como exemplo dessas experiências podemos citar o acordo sobre proteção de cilindros de massa na Cidade de São Paulo, o acordo de segurança em prensas mecânicas e equipamentos similares na região da Grande São Paulo. Essas negociações são formas alternativas de solução de conflitos nas relações entre capital e trabalho, criando comissões permanentes de negociação entre as partes envolvidas. Além da solução direta dos problemas identificados, as negociações têm produzido normas e padrões de saúde e segurança seja por intermédio da Associação Brasileira de Normas Técnicas (ABNT) seja com a criação de normas de saúde e segurança dos órgãos públicos envolvidos.

\section{Contexto da Experiência}

A SUCEN é a Autarquia de Saúde Pública do estado de São Paulo responsável pelo controle de doenças transmitidas por vetores. Essa instituição contava em 2002 com aproximadamente 1.400 funcionários, distribuídos em 11 Regionais do Estado, sendo que aproximadamente 6 oo servidores operavam diretamente no controle químico de vetores, como os que transmitem dengue, leishmaniose, malária, febre amarela e esquistossomose. Nessa atividade, os servidores aplicavam principalmente inseticidas do grupo de Piretroides e Organofosforados, utilizando-se de máquina de pulverização tipo costal motorizada (figura 1 e figura 2). Aproximadamente 700 servidores restantes atuavam em outras áreas tais como a administrativa e a pesquisa. A SUCEN executava suas atividades em todo o estado de São
Paulo. Para isso, dispunha de sede central na capital e de 10 Serviços Regionais, compostos de 32 sedes de setores e 19 Bases Operacionais, distribuídas em 51 cidades do Estado.

Os principais riscos ocupacionais encontrados nas diferentes atividades da Autarquia enquadramse entre os seguintes: riscos físicos (ruído, vibração, radiações não ionizantes e calor), químicos (inseticidas e produtos químicos outros utilizados em laboratório e limpeza), agentes mais relacionados à organização do trabalho (repetitividade, conflitos, esforço e carregamento de peso), biológicos e de acidentes.

Em 1998, a SUCEN contratou uma equipe técnica representada por médico do trabalho, engenheiro de segurança do trabalho e técnico de segurança

\section{Figura I - Desinsetizador da SUCEN em atividade}

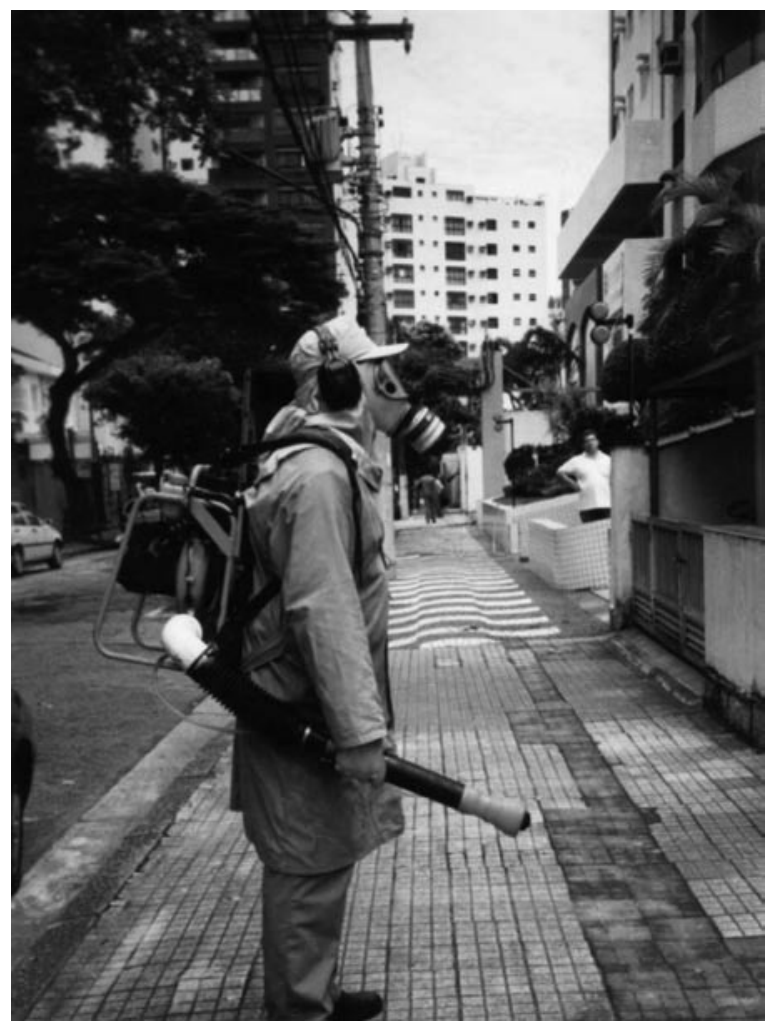

Dirigindo-se a uma residência. Ele carrega uma máquina de pulverização tipo costal motorizada para aplicação de inseticida usado no controle de epidemia de dengue. Usa vários EPIs desconfortáveis ainda necessários para minimizar as possibilidades de contaminação química e perda auditiva. 
Figura 2 - Desinsetizador da SUCEN em atividade

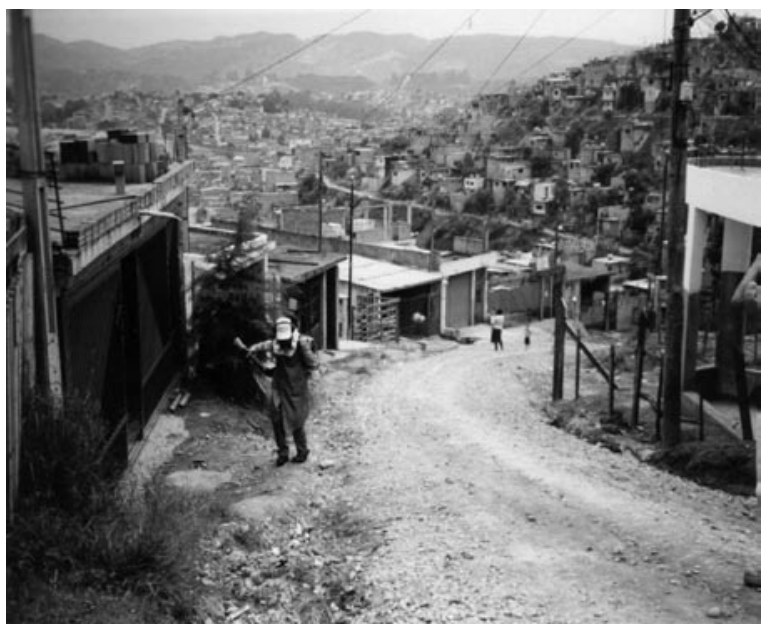

Em região onde realiza suas atividades de trabalho. Observa-se esforço para o deslocamento com carregamento de peso agravado pela dificuldade de acesso.

do trabalho, por meio de Convênio firmado com o Centro de Estudos Augusto Leopoldo Ayrosa Galvão (CEALAG) do Departamento de Medicina Social da Faculdade de Medicina da Santa Casa de São Paulo. Desde o início das atividades foi adotado pela equipe o método que contemplava técnicas gerenciais entendidas como gerenciamento participativo dos riscos. Este gerenciamento contempla a articulação dos esforços da equipe especializada com o respaldo do corpo dirigente da instituição, e participação dos trabalhadores e de seus órgãos de representação, especialmente das Comissões de Saúde do Trabalhador, as COMSAT's. Esse sistema participativo foi aprimorado no decorrer do tempo e culminou com a sua validação legal por meio de um acordo tripartite, cujo conteúdo está resumido no item de resultados.

\section{Objetivos}

- Descrever e analisar o modelo de gerenciamento participativo implantado na área de saúde do trabalhador;

- Apresentar e discutir os principais resultados advindos desse modelo na melhoria das condições de trabalho e na saúde dos trabalhadores.

\section{Método}

Trata-se de relato de experiência de natureza descritiva, que contou com a participação direta dos autores no decorrer de sua implantação. A descrição orienta-se por abordagem qualitativa que pode ser denominada "análise situacional", que se aplica a eventos sociais envolvendo vários sujeitos de uma comunidade ou organização (Becker, 1997; Triviños, 1995). Os dados quantitativos são apresentados no intuito de evidenciar e sustentar a argumentação. Como forma de acessar as informações, optou-se por análise documental (Lüdke e André, 1986), utilizando-se de relatórios, atas, planilhas e outros documentos produzidos e compilados pela equipe no decorrer do período de 1998 a 2002.

\section{Resultados}

\section{Estrutura, funcionamento e atribuições das COMSAT's}

Apoiando-se nesse modelo de gestão participativa, foram realizadas eleições de 11 Comissões de Saúde do Trabalhador (COMSAT's), alocadas nas sub sedes da SUCEN no estado de São Paulo que, conjuntamente com a equipe técnica, iniciaram a partir de 1998, a identificação e controle dos riscos nas atividades laborais da instituição. Para esta identificação e definição das prioridades os membros das COMSAT's após capacitação específica, ficaram encarregados de realizar reuniões com todos trabalhadores de sua região usando como referência o modelo italiano de mapeamento dos riscos encontrados nas situações e postos de trabalho. A partir do mapeamento as COMSAT's regionais tinham como tarefa identificar e encaminhar as prioridades para o nível central - COMSAT Estadual. Este fórum constituiu-se como espaço tripartite e paritário formado por representantes das COMSAT's Regionais, Gestores, equipe especializada e representação sindical do SINDSAÚDE/SP. Constituiu-se então num espaço de troca de experiência, supervisão e acompanhamento geral do processo de melhoria dos ambientes e processos de trabalho.

Após 4 anos de funcionamento, o Sistema de Gerenciamento Democrático e Participativo foi 
consolidado no Acordo Tripartite de Saúde dos Trabalhadores da Superintendência de Controle de Endemias - SUCEN/SP celebrado pela SUCEN/SP, Sindicato dos Trabalhadores da Saúde do Estado de São Paulo - SINDSAÚDE e Ministério do Trabalho e Emprego em 22/03/2002. Faz parte do acordo o Regimento interno das COMSAT's Regionais e COMSAT Estadual. Para o acesso à íntegra do documento ver no site: http://www.sindsaudesp.org.br/download/ documentos/ACORDO-TRIPARTITE.pdf

Conforme consta do Acordo Tripartite esta comissão substituiu na SUCEN as atribuições da Comissão Interna de Prevenção de Acidentes de Trabalho - CIPA, prevista pela legislação trabalhista vigente. Tratava-se de um organismo deliberativo no tocante às políticas de saúde do trabalhador buscando soluções para tornar compatível o trabalho com a preservação da vida e a promoção da saúde física e psíquica dos trabalhadores. Entre as principais atribuições das COMSAT's constou:

"I - Fazer o mapeamento da organização e processos de trabalho com a participação dos trabalhadores, identificando as condições de trabalho e ambientais que ofereçam riscos à segurança e à saúde dos trabalhadores e da comunidade; II - Elaborar plano de trabalho que possibilite a ação preventiva e a promoção de saúde e segurança, elencando medidas prioritárias que serão objeto de negociação para implementação junto à administração"(Acordo Tripartite citado, pag.3, 2002)

Os principais avanços comparados com a CIPA convencional foram assegurados pelos mecanismos resumidos a seguir:

- Eleição direta para todos os membros das COMSAT's incluindo dos presidentes;

- Ampliação dos mandatos dos eleitos para dois anos sendo livre a reeleição dos seus membros;

- Garantia do direito à informação dos riscos aos trabalhadores e representantes das COMSAT's;

- Os membros das COMSAT's tem direito ao acompanhamento das inspeções técnicas nos locais de trabalho com acesso à cópia dos relatórios/laudos;

- Aos representantes eleitos foi assegurado a proteção contra prejuízos funcionais, ou despedida arbitrária, desde a inscrição da candidatura até 1 ano após o término do mandato;

- Para as atividades de acompanhamento e inspeção das situações de trabalho foi assegurado tempo de 6 a 12 horas/mês durante a jornada normal de trabalho;

- Aos membros eleitos foi atribuído o direito a participação em cursos de capacitação sobre saúde do trabalhador a serem fornecidos por entidades específicas incluindo o Sindicato da Categoria;

- Direito do trabalhador recusar o trabalho em situação de Risco grave/eminente: assegurado pela participação e intermediação das COMSAT's.

Com esta metodologia e diretrizes, foi realizado nesse período o mapeamento dos riscos pelos trabalhadores e membros das COMSAT's, seguindo o modelo italiano que resultou em encaminhamentos e solução de importante número de problemas regionais e estaduais. 0 sistema de gestão democrático possibilitou também a elaboração de instruções normativas (conjunto de normas internas de procedimentos e orientações técnicas) que se destinaram à prevenção de acidentes e doenças relacionadas ao trabalho. Cada instrução normativa, antes de ser colocada em prática, foi amplamente discutida com membros das COMSAT's, com o corpo técnico e com os dirigentes da Autarquia. No período em análise (98-2002) foram elaboradas 20 instruções normativas (INs) e três informes técnicos. Esses 23 documentos, pelo importante valor técnico que lhes foi atribuído pela administração da empresa e pelos trabalhadores, ainda são atuais e representam nada menos do que $85 \%$ das 27 normas técnicas vigentes atualmente na instituição na área da Segurança do Trabalho, isto é, oito anos após o término do trabalho dessa equipe. Para o acesso de cada documento na íntegra pode ser consultado o site: <http://www. sucen.sp.gov.br/profi/insnor.html>.

Assim, vale a pena mencionar os documentos relacionados no Quadro 1.

Também foi viabilizado na mesma ocasião o Manual de Segurança Química em Controle de Vetores, texto de 90 páginas que incluiu uma síntese dos principais problemas decorrentes do transporte, armazenamento e manuseio de inseticidas e medidas de segurança aplicáveis em cada caso, que pode também ser consultado na integra no site <http://www. sucen.sp.gov.br/profi/segqui.html». 


\begin{tabular}{|l|}
\hline Normativa 1: lavagem e higienização das máscaras faciais \\
\hline Normativa 2: imunização \\
\hline Normativa 3: transporte de produtos perigosos \\
\hline Normativa 4: disposição de embalagens \\
\hline Normativa 5: normas e procedimentos para compra e uso das luvas nitrílicas \\
\hline Normativa 6: protetor auricular \\
\hline Normativa 7: EPIs necessários para as principais atividades da SUCEN \\
\hline Normativa 8: ficha de permissão para trabalhos com inseticidas \\
\hline Normativa 9: proteção respiratória \\
\hline Normativa 10: proteção para os pés \\
\hline Normativa 1I: ficha de controle de fornecimento de EPI \\
\hline Normativa 12: conjunto de EPIs para atividades de captura entomológica e malacológica \\
\hline Normativa 13: avaliação oftalmológica \\
\hline Normativa 14: prevenção das Lesões por Esforço Repetitivo \\
\hline Normativa 15: proteção contra hantavirus \\
\hline Normativa 16: proteção nos laboratórios de rotina \\
\hline Normativa 17: prevenção nas oficinas mecânicas \\
\hline Normativa 18: segurança nas atividades em altura \\
\hline Normativa 19: segurança em obras de construção civil nas dependências da SUCEN \\
\hline Normativa 20: procedimentos de segurança para o uso de pulverizadores \\
\hline Informe técnico ı: sobre as avaliações de acetilcolinesterase \\
\hline Informe técnico 2: avaliação da exposição ao ruido e medidas de controle \\
\hline Informe técnico 3: utilização de repelentes nas atividades de campo \\
\hline
\end{tabular}

Além da capacitação dos membros das COMSAT's, foi estruturado e ministrado na ocasião o Curso Básico de Saúde do Trabalhador, para o treinamento do conjunto de funcionários da Autarquia. Foram implantados o Programa de Prevenção de Riscos Ambientais (PPRA) e o Programa de Controle Médico de Saúde Ocupacional (PCMSO), que se integraram ao mapeamento de riscos elaborado pelas COMSAT's.

\section{Resultados práticos deste modelo de gerencia- mento}

Seguem nos Quadros e Tabelas algumas evidencias de avanços obtidos no período.

Na Tabela 1, relacionamos o número de recomendações sugeridas pelas COMSAT's no período de 1998 a 2001 para a melhoria das condições de trabalho e o número das que foram executadas ou estavam em execução ao final de 2002. Observa-se que o número de recomendações apontadas cresceu de forma expressiva a partir do primeiro ano, o que evidencia a convicção dos seus participantes nos resultados de suas propostas. A título de exemplificação, apresentamos no Quadro 2 uma relação de recomendações executadas e que foram consideradas de grande importância pelos trabalhadores.

Para as recomendações pendentes foram justificadas nas reuniões das COMSAT's os obstáculos por sua não execução. Após definição, relatórios e atas foram encaminhados para o nível responsável (Regional/Central). A grande dificuldade encontrada na execução da maioria das pendências situa-se na área econômica, ou seja, a falta de recursos financeiros encontrados nos órgãos públicos. As principais pendências referiam-se à execução de obras civis que dependiam de verbas e previsões orçamentárias, com prazos de viabilização a médio ou longo prazo. 
Tabela I - Balanço do andamento das recomendações das COMSAT's

\begin{tabular}{lccc} 
Ano & Recomendações sugeridas & Recomendações executadas ou em andamento & Percentual de itens executados* \\
1998 & 59 & 37 & 62,5 \\
1999 & 209 & 92 & 44,0 \\
2000 & 268 & 113 & 42,2 \\
2001 & 114 & 55 & 48,2 \\
\hline TOTAL & 650 & 297 & 45,7 \\
\hline
\end{tabular}

Fonte: Planilhas/Relatórios PPRA - SUCEN no período de 1998 a 200 .

* 0 percentual refere-se às recomendações executadas em relação às recomendações apontadas.

Quadro 2 - Recomendações propostas pelas COMSAT's e acatadas pela administração. SUCEN, 2002

\begin{tabular}{|l|}
\hline - Padronização, normatização e fornecimento periódico de equipamentos de proteção individual. \\
\hline - Convênio com instituição de pesquisa para alteração de equipamento de aplicação de inseticidas. \\
\hline - Desativação de depósitos de inseticidas e/ou oficinas inadequadas. \\
\hline - Reformas e/ou adaptações físicas em edificações. \\
\hline • Imunização para todos os servidores (vacinas antitetânica, contra hepatite B, febre amarela e gripe). \\
\hline - Aquisição de armários duplos para guarda de uniformes e EPIs. \\
\hline - Padronização/negociação com a administração pública para recolhimento de resíduos sólidos. \\
\hline - Negociação com fabricantes para devolução das embalagens de inseticidas. \\
\hline - Aquisição de mobiliário (cadeiras reguláveis) para os postos de trabalho de digitação. \\
\hline - Convênios com instituições públicas para realização de exames ocupacionais complementares. \\
\hline - Criação de comissão de Biossegurança para a padronização de procedimentos nos diferentes laboratórios da Autarquia. \\
\hline • Curso de capacitação no manejo de animais peçonhentos para os funcionários que executam atividades na mata. \\
\hline
\end{tabular}

Uma das necessidades também levantadas no início desse convênio foi a realização de exames periódicos para os servidores da SUCEN e elaboração/execução do Programa de Controle Médico de Saúde Ocupacional (PCMSO).

Na Tabela 2 estão apresentadas as porcentagens de cobertura dos exames efetuados para essa população. Apesar das distâncias geográficas existentes na SUCEN, entre as diferentes Regionais e seus respectivos Setores e Bases de Equipe, o empenho das Comissões de Saúde do Trabalhador, assim como da equipe técnica, contribuiu para a cobertura de pelo menos $86 \%$ nos 3 últimos anos.
Tabela 2 - Número de avaliações médicas periódicas e porcentagem de cobertura em relação ao total de funcionários

\begin{tabular}{ccc} 
Ano & $\begin{array}{c}N^{\circ} \text { de avaliações } \\
\text { médicas periódicas }\end{array}$ & $\begin{array}{c}\text { Porcentagem } \\
\text { de cobertura }\end{array}$ \\
1998 & 123 & 9,3 \\
1999 & 1255 & 95,5 \\
2000 & 1128 & 86,0 \\
2001 & 1207 & 92,0 \\
\hline
\end{tabular}

Fonte: Relatórios do PCMSO - SUCEN (1998-2002).

* 0 percentual de cobertura refere-se ao total de 1.314 funcionários. 
A Tabela 3 mostra o número de casos de Doenças Ocupacionais e/ou agravadas pela ocupação que foram identificados ano a ano.

\section{Tabela 3 - Principais casos de doenças ocupacionais e/ou relacionadas ao trabalho identificados nos ser- vidores da SUCEN}

\begin{tabular}{cccc} 
Ano & Reações alérgicas & LER/DORT & Distúrbios da audição \\
1998 & 10 & 3 & - \\
1999 & 42 & 31 & 59 \\
2000 & 10 & 18 & - \\
2001 & 4 & 16 & 33 \\
\hline
\end{tabular}

Fonte: Relatórios do PCMSO - SUCEN (1998 - 2002).

As reações alérgicas (respiratórias e cutâneas) referem-se a manifestações nasais na forma de Rinite, manifestações oculares na forma de conjuntivite e principalmente nas manifestações cutâneas na forma de queimação e prurido facial. Essas se relacionaram principalmente ao uso de inseticidas do grupo dos Piretróides. A diminuição significativa das reações alérgicas de 42 casos no biênio 1999/200o para 4 casos no biênio 2001/2002 foi creditada a/aos: 1) normatização e uso regular dos Equipamentos de Proteção Individual, com a introdução de máscara facial total em substituição à máscara semifacial nas atividades de aplicação; 2) implantação de Instruções Normativas que orientaram a manipulação segura dos equipamentos; 3) cursos de capacitação em Segurança e Saúde do Trabalhador, que a partir de 2001 abordaram com maior ênfase noções de toxicologia relacionadas aos inseticidas utilizados na SUCEN. Também em 2002, por motivos de resistência do vetor da Dengue - o mosquito Aedes aegypti - houve a necessidade de substituir o inseticida aplicado até então em algumas Regionais da Autarquia, ou seja, a Cipermetrina (Classe Toxicológica II - Piretroide) para o Malation (Classe Toxicológica III - Organofosforado). Esse último, com menor potencial alergênico.

As Lesões por Esforços Repetitivos - LER - diagnosticadas em 1999/200o, principalmente entre os servidores administrativos, levaram à elaboração da
Instrução Normativa $n^{0} 14$ - Prevenção de LER, para as atividades de digitação. Avalia-se que sua implantação tenha sido determinante para a redução do número de casos observado, de 31 (biênio 1999/200o) para 16 casos (biênio 2001/2002). A Instrução preconizava melhor distribuição da carga de trabalho entre os funcionários, de modo a evitar sobrecarga e pressão de tempo no final do mês, adoção de pausas periódicas além de melhorias no mobiliário.

Os Distúrbios Auditivos permaneciam como um dos principais problemas sem solução adequada até aquele momento. A máquina costal pulverizadora emitia um ruído que atingia níveis de 98 a 100 dB(A). Foi firmada, então, parceria com a Engenharia Mecânica da UNICAMP para avaliação e controle do ruído produzido pelo pulverizador costal. Foram efetuados vários testes com abafadores e mudança no escapamento do pulverizador sem, no entanto, conseguir a minimização das emissões sonoras, concluindo-se pela necessidade de reprojeto do referido equipamento pelo fabricante (Vilela e col., 2005).

Acredita-se que a redução das Disacusias no ano de 2001 esteja mais relacionada à baixa cobertura de exames audiométricos (37\%) alcançada nesse período do que à redução referente ao controle do risco. A baixa cobertura dos exames audiométricos foi atribuída a dois fatores: primeiro a distribuição dos funcionários em aproximadamente 50 Municípios no Estado de São Paulo, muitos dos quais desprovidos de serviços médicos qualificados para a realização deste exame que dificultava a cobertura e em segundo, as parcerias positivas, conseguidas no período 1999/200o com unidades ligadas ao Sistema Único de Saúde, para a realização dos exames audiométricos, não se confirmaram no período $2001 / 2002$.

Além das doenças profissionais acima descritas, as patologias de coluna vertebral também contribuíram para grande número de casos de trabalhadores que foram classificados como apresentando restrição ao retorno da função. Assim, a hérnia de disco, a protusão discal e as dorsalgias representaram as causas mais freqüentes de restrições. Em 1999 foram registrados 22 casos, em 2000, 39 e em 2001, 17. Essas restrições, em sua grande maioria, foram estabelecidas devido ao fato da máquina costal pulverizadora de inseticidas pesar 16 kg. Em relação à 
totalidade de restrições identificadas, vale citar que foi possível registrar uma importante diminuição. Assim, no ano de 2000 o número de restrições que havia chegado a 103 casos se reduziu no ano de 2001 para 41.

Dentre os motivos que mais contribuíram para a redução do número de restrições em 2001 foram os seguintes:

- Processos de readaptação funcional bem conduzidos;

- Troca dos equipamentos de proteção individual existentes anteriormente por outros mais apropriados para a atividade;

- Implementação das Instruções Normativas;

- Alteração da forma de organização do trabalho, incluindo melhoria na distribuição das tarefas e revezamento entre os membros da equipe durante a jornada.

\section{Prevenção de riscos no trabalho com inseticidas organofosforados}

Para o controle químico de vetores, em especial para o controle do mosquito transmissor da dengue, foram aplicados até o ano de 2001 e a metade de 2002 inseticidas do grupo dos Piretroides (basicamente a Cipermetrina). Diante da constatação do gradativo desenvolvimento de resistência desse vetor ao inseticida utilizado, houve necessidade de alteração para outro grupo químico, o dos organofosforados, mais especificamente para o inseticida Malation. 0 marcador biológico para esse grupo é a Acetil-colinesterase. A SUCEN efetuou parceria com instituição pública do estado de São Paulo para a realização desses exames. A equipe técnica, conjuntamente com o departamento de toxicologia desta instituição, elaborou um protocolo de coleta de material, assim como treinamento dos servidores que foram designados para efetuar o trabalho. Não havia sido registrado até outubro de 2002 nenhum caso de intoxicação crônica pelo inseticida Malation.

Dois casos de vazamento da máquina pulverizadora durante a execução da atividade resultaram em contaminação aguda de dois trabalhadores. Os acidentes resultaram no afastamento temporário destes trabalhadores uma vez que apresentaram diminuição da atividade da acetilcolinesterase
(30\% de redução) que ultrapassa o valor de alerta recomendado pela OMS.

\section{0 fornecimento de informação como base funda- mental para o sistema de gestão}

Foi praticada, neste período, política de transparência no tocante às informações para todos os envolvidos, e o esforço de capacitar o conjunto de funcionários para as questões de Segurança e Saúde dos Trabalhadores. Assim, todas as visitas técnicas foram realizadas com o acompanhamento dos representantes das COMSAT's e todos os relatórios produzidos tiveram uma via encaminhada para essas comissões. Os Cursos Básicos de Capacitação em Saúde do Trabalhador também envolveram, na sua realização, os membros das COMSAT's locais. Esses cursos eram compostos de duas partes: uma teórica e uma de trabalho em grupo, num período de 6 horas. No final dos cursos os participantes recebiam um questionário de avaliação escrita cujos resultados tabulados estão apresentados na Tabela 4. Como se pode observar dos 1.314 servidores da instituição, $1.003(76,3 \%)$ participaram pelo menos uma vez dos cursos básicos de Saúde do Trabalhador no período de 2000/2002, sendo que parte das regionais teve possibilidade de realizá-lo mais de uma vez. A soma das avaliações Bom e Ótimo pelos servidores que participaram representou um valor de 9o,8\%. Vale ressaltar que os servidores da regional SR o2, avaliaram o curso como Ruim, em decorrência dos problemas de caráter político-administrativos com a Direção Regional da SUCEN que impossibilitaram um bom aproveitamento do mesmo. Excetuando-se esse caso, de forma geral, interpreta-se a avaliação da atividade como muito boa.

\section{Discussão}

Os resultados indicam que mesmo diante de dificuldades financeiras por que passa a administração pública, o método participativo de gestão em Segurança e Saúde do Trabalhador, implantado na SUCEN no período de 1998 a 2002 mostrou ser eficiente na gestão e controle dos riscos relacionados ao trabalho.

O envolvimento e o compromisso obtido nos diferentes níveis hierárquicos, o reconhecimento do 
Tabela ${ }_{4}$ - Balanço da participação e avaliação dos Cursos Básicos de Capacitação em Saúde do Trabalhador

\begin{tabular}{lccc}
$\begin{array}{l}\text { Unidade regional } \\
\text { Sede }\end{array}$ & $\begin{array}{c}N^{0} \text { de servidores } \\
\text { por unidade }\end{array}$ & $\begin{array}{c}N^{0} \text { de trabalhadores que } \\
\text { participaram dos cursos }\end{array}$ & $\begin{array}{c}\text { Avaliação - Soma das \% das } \\
\text { avaliações Bom e ótimo }\end{array}$ \\
DPE* & 136 & 93 & 95,0 \\
SR 02* & 106 & 85 & 93,6 \\
SR03 & 143 & 128 & 52.0 \\
SR 04* & 93 & 85 & 95,2 \\
SR 05* & 75 & 56 & 95.0 \\
SR 06 & 145 & 98 & 90.2 \\
SR 08* & 130 & 88 & 93,3 \\
SR 09 & 142 & 86 & 94,0 \\
SR 10* & 110 & 100 & 96,7 \\
SR II & 94 & 94 & 100,0 \\
\hline TOTAL & 140 & 90 & 94,0 \\
\hline
\end{tabular}

Fonte: Relatórios SESMT - SUCEN (2000-2002).

* Regionais que já tiveram curso de reforço.

saber dos trabalhadores, assim como a coerência entre o discurso e as práticas de prevenção e melhoria das condições de trabalho, premissas desse sistema de gestão, alicerçam os resultados obtidos, os quais se avaliam como positivos.

Ao ouvir os trabalhadores o modelo renova o olhar sobre o trabalho:

- o processo de normatização é efetuado de baixo para cima e recolhe informações sobre a situação real de trabalho, ou seja, o que orienta as transformações são as necessidades reais e não uma motivação burocrática de atenção aos preceitos legais;

- as prioridades são definidas em conjunto e validadas nos próprios grupos e não de modo unilateral baseado no saber do especialista.

Longe de esgotar todas as demandas e necessidades, como, por exemplo, a questão do ruído, foi possível o encaminhamento e equacionamento dos principais problemas, representando assim um primeiro passo na busca de um ambiente de trabalho seguro e saudável.

Com o sistema participativo de gestão em Saúde do Trabalhador, a SUCEN aplica em "casa" as diretrizes preconizadas pelo SUS para a área de atenção integral e vigilância em saúde do trabalhador.
Em função das reestruturações por que passam o sistema público de saúde, principalmente no estado de São Paulo, como, por exemplo, a crescente transferência de atividades de controle de epidemias do nível estadual para os municípios, acredita-se que a gestão de segurança e saúde do trabalhador, implantada na SUCEN, possa ser útil principalmente para as atividades descentralizadas desse sistema, como forma efetiva de minimização dos riscos existentes em suas atividades.

As COMSAT's na SUCEN mostraram-se na prática mais atuantes e democráticas que as CIPAS previstas pela Consolidação das Leis do Trabalho, onde se percebe, com raras exceções, um papel burocrático e esvaziado enquanto mecanismo de promoção e prevenção da saúde, que se explica, entre outras razões, pela subordinação e falta de autonomia frente aos ditames do empregador.

A experiência aqui relatada inspirou as negociações que resultou na implantação de COMSAT's em todas as unidades, hospitais e autarquias da rede pública estadual, conforme consta da Resolução da Secretaria de Estado da Saúde (SS-5, de 16/01/2006).

Mesmo não sendo mantidos todos os avanços ocorridos na SUCEN, o SINDSAÚDE/SP considera 
que a reprodução da experiência para a rede estadual de saúde é uma "importante conquista dos trabalhadores públicos da saúde no estado de São Paulo" (SINDSAÚDE/SP, 2010, p. 5).

A despeito dos avanços no processo de participação para a negociação e acompanhamento das melhorias conforme prevê o Acordo Tripartite, o agrupamento dos fatores de risco, que instrui o mapeamento de riscos acompanha na prática o modelo italiano, que ainda mantém em essência os mesmos grupos de risco da saúde ocupacional. Este agrupamento é orientado por uma análise de tipo fatorial que isola agentes ambientais do processo de trabalho, abordagem que descaracteriza a determinação social da organização do trabalho (Laurell e Noriega, 1989).

Com a troca da equipe técnica em 2002 e provável retorno a práticas de gestão do tipo convencional, é de se esperar que tenham ocorrido retrocessos no processo participativo, sendo necessárias novas avaliações da experiência.

\section{Agradecimentos}

Dedicamos este artigo ao amigo Dr. Walter Takashi Tsunaki (em memória), um dos protagonistas do sistema democrático aqui relatado. Agradecemos a todos os funcionários da SUCEN que partilharam desta experiência.

\section{Referências}

BECKER, H. S. Métodos de Pesquisa em Ciências Sociais. 3. ed. São Paulo: Hucitec, 1997, 178p.

BONCIANI, M.(org.). Saúde, ambiente e Contrato Coletivo de Trabalho - Experiências em negociação coletiva. São Paulo: LTR, 1996.

BRASIL. Ministério da Saúde. Portaria $n .^{\circ} 3.120$ de o1 de julho de 1998. Brasília: Ministério da Saúde, 1998. Instrução normativa sobre ações de vigilância em saúde do trabalhador no SUS.

LAURELL, A. C.; NORIEGA, M. Processo de produção e saúde: trabalho e desgaste operário. São Paulo: Hucitec, 1989, 333 p.

LUDKE, M.; ANDRÉ, M. Pesquisa em Educação: abordagens qualitativas. São Paulo: EPU, 1996.
MAGRINI, R. O. Novas relações trabalhistas de segurança e saúde do trabalhador desenvolvidas no Estado de São Paulo e no Brasil. 1999. 216 f. Tese (Doutorado) - Faculdade de Filosofia, Letras e Ciências Humanas, Universidade de São Paulo, São Paulo, 1999.

MINAYO-GOMEZ, C.; THEDIM-COSTA, S. M. F. A construção do campo de saúde do trabalhador: percurso e dilemas. Cadernos de Saúde Pública, Rio de Janeiro, v. 13(Supl.2), p. 21-32, 1997.

ODDONE I. et al. Ambiente de trabalho: a luta dos trabalhadores pela saúde. São Paulo: Hucitec, 1986, $133 \mathrm{p}$.

SINDSAÚDE/SP - Sindicato dos Trabalhadores Públicos da Saúde no Estado de São Paulo SINDSAUDE/SP. COMSAT - Comissão de Saúde do Trabalhador. Saúde para o trabalhador da saúde. Disponível em: <http://www.cntsscut.org. $\mathrm{br} /$ download/Comsat-Sindsaude-SP>. Acesso em: 10 dez. 2010.

TRIVIÑOS, A. N. S. Introdução à pesquisa em ciências sociais: a pesquisa qualitativa em educação. São Paulo: Atlas, 1995, 175 p.

VILELA, R. A. G. Negociação coletiva e participação na prevenção de acidentes do trabalho, estudo da Convenção Coletiva de Segurança em Máquinas Injetoras de Plástico do Estado de São Paulo. 1998. Dissertação (Mestrado em Saúde Coletiva) - Faculdade de Ciências Médicas, Universidade de Campinas - UNICAMP, Campinas, 1998.

VILELA, R. A. G; MALAGOLI, M. E.; MORRONE, L. C. Trabalhadores da saúde sob risco: o uso de pulverizadores no controle de vetores. Produção, São Paulo, v. 15, n. 2, p. 263-272, maio-ago. 2005.

VILELA, R. A. G.; MARTINS, P. Saúde do trabalhador e meio ambiente no contexto da globalização In: BONCIANI, M. (org.). Saúde, ambiente e contrato coletivo de trabalho. São Paulo: LTR; 1996. p. 46-70.

Recebido em: 11/01/2010 Reapresentado em: 30/08/2010 Aprovado em: 07/09/2010 